A influência da fala na escrita das oclusivas:

o papel do VOT em trocas ortográficas $\mid 85$

\title{
A INFLUÊNCIA DA FALA NA ESCRITA DAS OCLUSIVAS: O PAPEL DO VOTEM TROCAS ORTOGRÁFICAS
}

\author{
Vergília Spiering Damés1 \\ Giovana Ferreira-Gonçalves ${ }^{32}$
}

RESUMO: As trocas ortográficas verificadas nos segmentos oclusivos parecem estar além dos dois tipos principais de erros ortográficos: aqueles decorrentes da complexidade do sistema ortográfico e aqueles decorrentes de influência da fala na escrita. Observando com maior detalhamento os aspectos acústicos desses sons, em especial a duração de VOT, é possível que se estabeleça relação entre a fala e a troca desses grafemas na escrita, conforme já indiciam Sanches (2003) e Cristofolini (2008). A fim de confirmar tal hipótese, foram coletados dados de fala e escrita de 47 participantes matriculados nos $2^{\circ}, 3^{\circ}, 4^{\circ}$ e $6^{\circ}$ anos do Ensino Fundamental de uma escola pública de Pelotas/RS. O instrumento utilizado possibilita a análise de fala e escrita controlada e espontânea. Os dados revelaram que as trocas ortográficas nos segmentos oclusivos são reduzidas, mas, ainda assim, em número superior as constatadas na oralidade. Por meio de análise acústica, considerando a duração do VOT, verificou-se que o VOT das oclusivas dorsais parece ser aquele com maior indício de refinamento articulatório, o que indiciaria um papel da fala na escrita dos segmentos plosivos. No entanto, quanto às oclusivas labiais e coronais, os resultados não parecem indicar a influência da oralidade na ocorrência de trocas ortográficas.

Palavras-chave: Trocas ortográficas. Oclusivas. Voice Onset Time

ABSTRACT: The orthographic changes observed in the stops segments seem to be beyond the two main types of orthographic errors: those due to the complexity of the orthographic system and those resulting from the influence of speech on the spelling. It is possible to establish a relation between speech and the orthographic changes in writing, as Sanches

\footnotetext{
${ }^{31}$ Doutoranda em Letras pela Pontifícia Universidade Católica do Rio Grande do Sul-PUCRS/CNPq. Mestra em Letras pela Universidade Federal de Pelotas-UFPel/FPAERGS/CAPES.

32 Professora Associada na Universidade Federal de Pelotas-UFPel. Bolsista de Produtividade do CNPq.
} 
(2003) and Cristofolini (2008) have already pointed out the acoustic aspects of these sounds, especially VOT duration. In order to confirm this hypothesis, we collected oral and written data from 47 students enrolled in the $2 \mathrm{nd}, 3 \mathrm{rd}, 4 \mathrm{th}$ and 6 th grades of primary school from a public school located in Pelotas/RS. The instrument used enables to analyze controlled and spontaneous speech and writing. The data revealed that the orthographic changes in the stops segments occur in a small number, nevertheless, this number is higher than those observed in oral data. By acoustic analysis, considering the duration of VOT, it was verified that the VOT of the dorsal occlusives seems to be the one with the greatest articulatory refinement, which would indicate a role of speech in the writing of the plosive segments. However, for the labial and coronal plosives, the results do not seem to indicate the influence of orality on the occurrence of orthographic changes.

Keywords: Orthographic changes. Stops. Voice Onset Time

\section{Introdução}

A ocorrência de erros ortográficos ganha destaque aos olhos dos professores nos anos iniciais do Ensino Fundamental I quando passa a ser frequente a sua presença. Em geral, as construções diferentes do esperado são resultantes (i) da complexidade do sistema ortográfico ou (ii) da influência da fonologia ou fonética (ZORZI, 1997; GUIMARÃES, 2005; MIRANDA, 2010; 2014). Os classificados em (ii) serão aqui discutidos, destacando-se a relação entre fala e escrita.

Sabe-se que a escrita carece de instrução explícita para que sua aprendizagem seja concretizada, ao contrário da fala. Não por acaso, durante sua etapa de sistematização, a criança tende a recorrer à fala, dentre outros artifícios, passando a tê-la como auxiliar na construção de suas primeiras hipóteses acerca da escrita (MIRANDA; MATZENAUER, 2010; ABAURRE, 2011). Uma das principais evidências dessa relação é que as etapas pelas quais a aquisição da escrita passa são similares àquelas observadas durante a aquisição da fala (ABAURRE, 2011).

No entanto, nem sempre o papel da fala é observado de modo direto, como, por exemplo, quando a criança escreve menino como mininu por influência explícita da oralidade. Há casos, como pode ser constatado ao observarmos as trocas que ocorrem com os segmentos oclusivos (DAMÉ, 2016; DAMÉ; FERREIRA-GONÇALVES, 2017; 2018), em que 
o papel da oralidade só é constatado quando utilizamos outras ferramentas metodológicas, como a inspeção acústica dos dados.

É esperado que a produção da fala desses segmentos já esteja estável em nível escolar e não sejam verificadas de outiva mudanças na fala, logo, trocas na ortografia não seriam decorrentes dessas. Sanches (2003), Cristofolini (2008) e Damé (2017) indicam a possibilidade da influência de aspectos fonético/fonológicos na ocorrência dessas trocas, sendo reflexo de uma estabilização na duração do VOT nas produções desses sujeitos.

A fim de verificar a hipótese levantada, foram coletados dados de fala e escrita de 47 estudantes matriculados nos $2^{\circ}, 3^{\circ}, 4^{\circ}$ e $6^{\circ}$ anos do ensino fundamental de uma escola da rede pública localizada em Pelotas. A partir de tais dados, pretende-se observar se o VOT tem papel na ocorrência de trocas ortográficas e se a influência se estende para todas as oclusivas, independente do contexto em que aparecem, ou é restrita a algum ambiente linguístico específico, como tipo de sílaba e tonicidade.

Na seção que segue esta introdução, será realizada uma retomada de aspectos relativos às oclusivas, no que concerne à escrita e à fala, seguida de uma explanação sobre o VOT e sua importância para esses segmentos. A terceira seção destina-se à metodologia aplicada para coleta de dados e, por fim, serão apresentados os dados, juntamente com os resultados obtidos, para que sejam tecidas as principais conclusões.

\section{A fala e a escrita das oclusivas no PB}

O comportamento dos segmentos oclusivos durante a aquisição da fala e da escrita é capaz de oferecer alguns indícios a respeito da relação entre ambas na ocorrência de trocas ortográficas.

$\mathrm{Na}$ fala, as oclusivas são as primeiras consoantes adquiridas, por volta dos 1:6 e 1:8 (anos:meses) (LAMPRECHT, 1990; FREITAS, 2004; BONILHA, 2004), podendo apresentar uma pequena diferença de tempo entre uma e outra a depender de seu ponto de articulação. Lamprecht (1990) aponta a emergência de oclusivas labiais e coronais antes das dorsais, assim como dos segmentos surdos antes dos sonoros. Freitas (2004), ao observar distintos estudos acerca desses segmentos, salienta tendência à ocorrência de três estágios de aquisição: (i) $/ \mathrm{p} /, / \mathrm{t} /, / \mathrm{k} /$; (ii) $/ \mathrm{p} /, / \mathrm{b} /, / \mathrm{t} /, / \mathrm{d} /, / \mathrm{k} /$; (iii) $/ \mathrm{p} /, / \mathrm{b} /, / \mathrm{t} /, / \mathrm{d} /, / \mathrm{k} /, / \mathrm{g} /$. 
Sob um ponto de vista dinâmico, essa aquisição não seria estabilizada tão cedo, passando ainda por um longo período de refinamento articulatório (CRISTOFOLINI, 2013; SANCHES, 2003). Cristofolini (2013) relata, a partir de análise acústica, que, aos 6:0, menor faixa etária considerada em seu estudo, somente [b] tem o padrão gestual estável. A oclusiva velar surda parece ser aquela com maior instabilidade em sua produção. Essa instabilidade nos segmentos surdos também é atestada por Bonatto (2007), que prevê uma estabilização posterior a das ocluisvas sonoras, devido à dificuldade na sistematização dos gestos envolvidos nesses sons, já que a criança precisa interromper um gesto de glote ou de protusão labial para dar início a outro.

No que diz respeito à escrita, os segmentos oclusivos são conhecidos por serem aqueles que apresentam, em geral, uma relação biunívoca entre letra e som, ou seja, apenas um grafema representando cada som, com exceção de "g" e "k' que, seguidas de "i", precisam do dígrafo para compor seu grafema. Os erros verificados nesses segmentos são tema de distintos estudos (ZORZI, 1997; GUIMARÃES, 2005; MIRANDA; MATZENAUER, 2010), revelando a influência da fonologia, e, em sua maioria, são verificados e divididos em três categorias: trocas na relação surda/sonora, mudança de ponto de articulação e omissão de letras.

O estudo de Zorzi (1997) revela que as trocas, quando considerados os segmentos oclusivos, ocorrem em sua maioria na relação surda/sonora e com os segmentos dorsais, seguidos dos coronais e labiais. Também aponta que a maioria dos casos é de dessonorização, ou seja, mudança de um som sonoro para surdo. No mais, reflete que as trocas tendem a ser recorrentes em um número pequeno de sujeitos, considerando os 514 que compõem seu corpus, o que pode justamente indicar uma influência da fala.

Guimarães (2005) apresenta resultados similares com maior concentração de trocas nas oclusivas dorsais e menor nas labiais, assim como Miranda e Matzenauer (2010). Essas autoras destacam, ainda, que a dessonorização, assim como apontado por Zorzi (1997), se mantém sendo mais recorrente, em especial para as dorsais e labiais; no caso das coronais, a sonorização ocorre em maior número.

Os trabalhos descritos lidam separadamente com os segmentos oclusivos na fala e na escrita. Desse modo, é preciso não só observar o que já foi dito sobre a relação entre fala e escrita mas, em especial, sobre a 
A influência da fala na escrita das oclusivas:

o papel do VOT em trocas ortográficas | 89

importância do VOT, principal pista acústica considerada quanto se trata das oclusivas, para a ocorrência de trocas ortográficas.

\section{Relação entre fala e escrita: VOT e sua importância para as oclusivas}

A relação entre fala e escrita pode muitas vezes ser destinada a uma influência direta, no entanto, estudos de cunho dinâmico evidenciam que a erros de escrita podem ser resultado da gradiência na produção dos gestos articulatórios responsáveis pela constrição da oclusiva. Assim sendo, imprecisões de ordem fonético/fonológica podem dar conta de erros que, embora não sejam percebidos de outiva, podem ser identificados por meio de análise acústica (SANCHES, 2003; CRISTOFOLINI, 2008; RODRIGUES, 2012).

No que concerne às oclusivas, a pista acústica que desponta mais interesse é o VOT (Voice Onset Time), parâmetro estabelecido por Lisker e Abramson (1954) como passível da classificação das oclusivas de diferentes línguas em três categorias: (i) pré-sonorização - quando o vozeamento é anterior à soltura da constrição dos articuladores; (ii) retardo curto - quando o vozeamento é concomitante ou imediatamente após a soltura da constrição dos articuladores; e (iii) retardo longo quando o vozeamento é após a soltura da constrição dos articuladores. Essas três categorias podem ser denominadas, também, como VOT (-), $\operatorname{VOT}(0)$ e VOT (+), respectivamente.

No Português, o estudo de Klein (1999) é basilar quando se trata da duração de VOT da fala adulta. Realizado em Santa Catarina, apresenta um panorama de como o VOT se comporta no Português Brasileiro (PB) falado nesse local. A classificação destinada ao PB seria de VOT ( - ) para as oclusivas sonoras e VOT (0) para as surdas. A primeira é confirmada por Klein (1999), mas a classificação das surdas, em especial a dorsal, já tende a apresentar um VOT (+). Tal trabalho será aqui utilizado como base para verificar o VOT da fala infantil.

Os estudos que lidam com a fala infantil e sua relação com a escrita tomados como base são os realizados por Sanches (2003) e Cristofolini (2008). Os valores médios de VOT desses trabalhos, com adição de Klein (1999), serão explanados a fim de evidenciar o padrão adulto e demonstrar que o valor de VOT da fala infantil apresenta diferenças, justamente por estarem esses sujeitos em processo de aquisição. 
Cristofolini (2008) evidencia o predomínio de trocas, no que se refere à sonoridade, nas oclusivas coronais e dorsais. Ao verificar os contextos linguísticos controlados, reporta a relevância do contexto tônico, ambiente em que ocorrem a maioria das trocas, tanto no texto espontâneo como no ditado, as duas modalidades de coleta realizadas. $\mathrm{O}$ contexto vocálico mais propício à ocorrência de trocas de sonoridade é, nos textos espontâneos, a vogal "i" e, no ditado, a vogal "a". Os encontros consonantais representam menos de $10 \%$ das trocas encontradas.

No que concerne à análise acústica dos dados de fala, foi verificada uma maior duração média do VOT para o grupo controle. Quando submetidos à análise estatística, os dados revelaram a presença de diferença significativa entre os dois grupos - controle e trocas - para a produção das oclusivas dorsais, surdas e sonoras, e coronais surdas, ou seja, aquelas que apresentaram um maior número de trocas na escrita. Os valores médios de VOT apresentados no grupo controle - aquele que não apresentava trocas ortográficas - e o grupo trocas - aquele em que os participantes apresentavam trocas ortográficas - estão dispostos na Tabela 1.

Tabela 1: Médias de duração de VOT na fala adulta e infantil

\begin{tabular}{|c|c|c|c|c|c|c|c|}
\hline \multirow{2}{*}{\multicolumn{2}{|c|}{ Estudo }} & \multicolumn{6}{|c|}{ Média (ms) } \\
\hline & & [p] & [b] & [t] & [d] & {$[\mathrm{k}]$} & []] \\
\hline 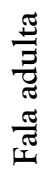 & $\begin{array}{c}\text { Klein } \\
\text { (1999) }\end{array}$ & 15,58 & 92,27 & 16,69 & 92,07 & 36,36 & $-78,20$ \\
\hline \multirow{2}{*}{ 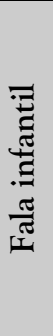 } & $\begin{array}{c}\text { Cristofolini } \\
\text { (2008) - } \\
\text { Grupo } \\
\text { controle } \\
\end{array}$ & 21,09 & 81,17 & 23,37 & 70,38 & 31,81 & $-76,87$ \\
\hline & $\begin{array}{c}\text { Cristofolini } \\
(2008)- \\
\text { Grupo } \\
\text { trocas }\end{array}$ & 20,97 & $\begin{array}{c}- \\
77,79\end{array}$ & 20,54 & 70,23 & 29,78 & $-69,61$ \\
\hline
\end{tabular}

Fonte: Elaborado pelas autora a partir das fontes citadas 
Após análise estatística, Cristofolini (2008) constatou diferenças significativas para a duração do VOT entre o grupo controle e o grupo trocas, além disso, esse último apresentou maior número de inadequações acústicas, como, por exemplo, a presença de múltiplos bursts em oclusivas coronais e labiais surdas e sonoras. Sendo assim, a relação entre fala e escrita parece ser positiva, podendo uma produção articulatória diferenciada refletir na escolha do grafema adequado para representar um dado som.

Na mesma direção, estão os resultados encontrados por Sanches (2003), em trabalho destinado à análise espectrográfica da fala de crianças que apresentam trocas ortográficas nas oclusivas surdas e sonoras. A autora revela que, para as oclusivas sonoras, o valor de VOT $(-)$ tem uma duração menor do que aquela apresentada pela literatura em geral, chegando a apresentar casos em que há VOT (0) e VOT (+), característicos de oclusivas surdas, quando o início da sonorização é concomitante ou posterior à soltura da oclusiva. Esses valores diferenciados de VOT parecem refletir na ocorrência de trocas ortográficas, pois os sujeitos passam a ter dificuldade para diferenciar a sonoridade desses segmentos.

Sendo assim, diante da complexidade imbricada na relação entre fala e escrita, e levando em conta que a escrita pode sofrer influência de imprecisões de ordem fonética/fonológica presentes na fala, faz-se necessário observar o possível papel do VOT para a ocorrência de trocas ortográficas quando se trata dos segmentos oclusivos.

\section{Metodologia}

A coleta de dados para obtenção dos dados de escrita e fala foi realizada em ambiente escolar com 47 alunos, matriculados nos $2^{\circ}, 3^{\circ}, 4^{\circ}$ e $6^{\circ} \operatorname{anos}^{33}$ do ensino fundamental de uma escola pública localizada na cidade de Pelotas/RS. O objetivo inicial era manter 15 alunos em cada turma, mas por vezes o número de alunos da turma ou de alunos

33 O $5^{\circ}$ ano não compõem o corpus por não fazer parte das turmas participantes do projeto PICMEL, a ser descrito ao longo da metodologia, tendo sido desconsiderado por tratar-se de uma fase de transição na escola, quando os alunos passam a ter professores específicos para cada disciplina. 
92 |Vergília Spiering Damé e Giovana Ferreira-Gonçalves

autorizados não foi suficiente, de forma que esses 47 participantes estão distribuídos conforme exposto no Quadro 1.

\section{Quadro 1: Número de participantes por turma}

\begin{tabular}{|c|c|}
\hline Turma & Número de sujeitos \\
\hline $2^{\circ}$ ano & 8 \\
\hline $3^{\circ}$ ano & 13 \\
\hline $4^{\circ}$ ano & 16 \\
\hline $6^{\circ}$ ano & 10 \\
\hline Total & 47 \\
\hline
\end{tabular}

Fonte: Elaborado pela autora

Primeiramente foi realizada a coleta de dados de fala, com a produção de uma narrativa pelos participantes, na qual contavam uma história a partir de imagens, conforme Figura 1. Tal atividade buscava observar como o participante realizava os segmentos quando tinha a possibilidade de escolher as palavras que iria utilizar.

Figura 1: Imagens que compõem a narrativa
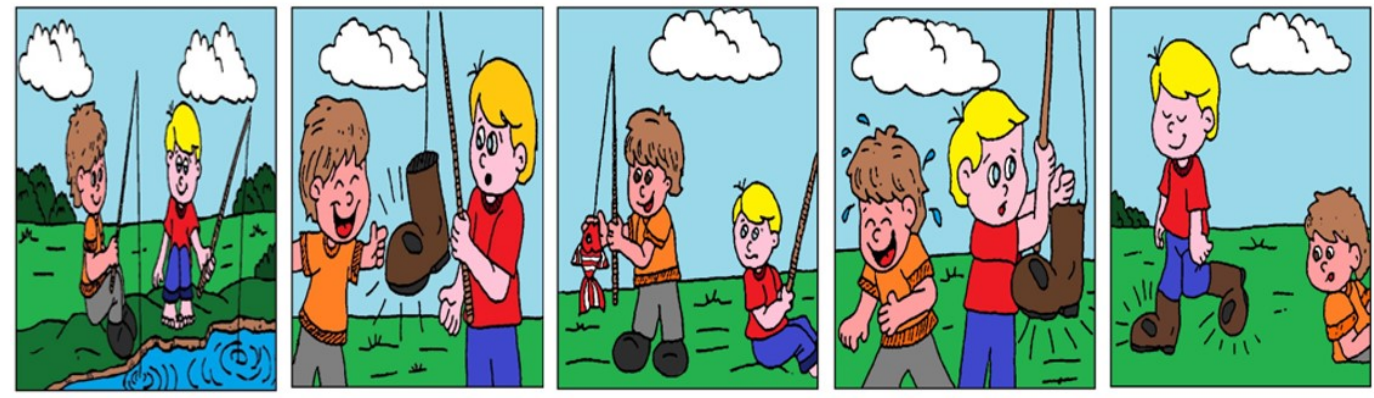

Fonte: Adaptado pela autora ${ }^{34}$

$\mathrm{Na}$ sequência, foi proposto um ditado de imagens com 233 palavras, exibidas aos alunos por meio de um notebook, que foram

34 Figura obtida no Google Imagens em preto e branco e colorida digitalmente. Disponível em: http://princesa212010.blogspot.com/2010/08/producao-de-texto.html. 
produzidas uma vez em uma frase-veículo: Digo palavra-alvo para você. Essas palavras são constituídas por consoantes oclusivas: (i) seguidas das vogais "a", "i", "u"; (ii) em sílaba com estrutura CV e CCV - seguida da líquida lateral e não lateral; (iii) em sílaba tônica e átona; e (iv) em posição inicial e medial na palavra. Considerando que nem todos os contextos foram preenchidos, seja por falta de uma palavra conhecida ou pela impossibilidade de representação por meio de figuras, o número de ocorrências para cada oclusiva é o disposto no Quadro 2.

Quadro 2: Número de ocorrências por oclusiva no ditado de imagens da primeira etapa

\begin{tabular}{|c|c|c|c|}
\hline Oclusiva & Ocorrências & Oclusiva & Ocorrências \\
\hline$[\mathrm{p}]$ & 49 & {$[\mathrm{~b}]$} & 49 \\
\hline$[\mathrm{t}]$ & 34 & {$[\mathrm{~d}]$} & 24 \\
\hline$[\mathrm{k}]$ & 43 & {$[\mathrm{~g}]$} & 34 \\
\hline Total & 126 & Total & 107 \\
\hline
\end{tabular}

Fonte: Elaborado pela autora

Considerando-se o número de sujeitos e o total de segmentos alvo, o objetivo era coletar 10.951 tokens nessa etapa, sendo 5.922 relativos às oclusivas surdas e 5.029, às sonoras.

Essas atividades foram realizadas individualmente e registradas por meio dos gravadores Zoom H4N e Roland R-05, com taxa de amostragem de $44.100 \mathrm{~Hz}$.

Os dados de escrita levaram em conta as mesmas atividades, no entanto, a coleta foi realizada em sala de aula, com toda a turma (apenas os dados daqueles alunos que tinham autorização foram utilizados), com as imagens exibidas por meio de um Datashow.

As coletas de dados realizadas são parte integrante do Projeto PICMEL (Programa de Iniciação a Ciência, Matemática, Engenharias e Letras $^{35}$ e todos os participantes foram autorizados a realizar os procedimentos previstos mediante Termo de Consentimento Livre e Esclarecido assinado por seus responsáveis.

35 Projeto PICMEL-FAPERGS/CAPES, coordenado pela Profa. Dr. Giovana Ferreira-Gonçalves (UFPel), processo nº. 0340-2551/14-6. 
Para análise dos dados, foi considerada uma amostra reduzida, disposta no Quadro 3, sobre a qual foram realizadas (a) análise acústica, em que foram consideradas medidas de duração de VOT feitas no Praat (v. 2.16.11); (b) análise estatística, por meio do software SPSS Statistics (v. 17.0), em que foram comparadas as medidas de duração de VOT e sua duração relativa ${ }^{36}$, sendo considerado significativo o valor de $p$ menor do que 0.05 . A análise acústica foi realizada com 22 sujeitos, distribuídos em 2 grupos, um com trocas na escrita e outro sem. Cada grupo contou com 3 alunos nos $2^{\circ}, 3^{\circ}$ e $4^{\circ}$ anos e 2 no $6^{\circ}$.

Quadro 3: Palavras selecionadas para compor a análise acústica ${ }^{37}$

\begin{tabular}{|c|l|c|c|c|c|c|}
\hline Contexto & \multicolumn{1}{|c|}{$[\mathrm{p}]$} & {$[\mathrm{b}]$} & {$[\mathrm{t}]$} & {$[\mathrm{d}]$} & {$[\mathrm{k}]$} & {$[\mathrm{g}]$} \\
\hline $\mathrm{CV}-\mathrm{a}$ & Palha & Bala & Taça & Dama & Casa & Galo \\
\hline CrV - a & Praça & Braço & Trave & Drácula & Cravo & Grávida \\
\hline CV - i & Pilha & Bicho & & & Quilo & Guia \\
\hline CrV - i & Primo & Briga & Trilha & Drible & Crise & Grilo \\
\hline CV - u & Pulo & Bule & Túnel & Duas & Cuia & Gude \\
\hline CrV - u & & Bruxa & Trufa & & Crua & Grupo \\
\hline
\end{tabular}

Fonte: Elaborado pela autora

Das 233 palavras iniciais, foram selecionadas 32, apresentadas no Quadro 3, que contém as seis oclusivas dispostas em início de palavra, sílaba tônica, seguidas das vogais “a”, "i” e "u”, em sílaba CV e CCV. Esse recorte foi realizado para compor um grupo controle e verificar se haveria presença de imprecisões fonético/fonológicas mesmo quando as palavras analisadas não eram aquelas em as trocas foram verificadas. A partir da produção dos 22 sujeitos, seriam esperados 704 tokens, mas foram analisados 431, considerando descartes por impossibilidade de análise

\footnotetext{
${ }^{36}$ Para realização da medida de duração relativa, seguiu-se o proposto por Cristofolini (2013), calculando-a por meio de: duração do VOT/duração da palavra * 100 .

${ }^{37}$ As colunas não preenchidas tratam-se de contextos que não dispunham de uma palavra de fácil reconhecimento por meio de uma imagem e/ou por uma criança, à exceção de [t] e [d] seguidos de [i], desconsiderados por conta da palatalização dessas consoantes nesse contexto na região em que os dados foram coletados.
} 
A influência da fala na escrita das oclusivas:

o papel do VOT em trocas ortográficas | 95

acústica ou não produção do dado. No Quadro 4 estão dispostos os tokens que foram analisados por oclusiva.

Quadro 4: Número de dados submetidos à análise acústica divididos por oclusiva e grupos com trocas e sem trocas

\begin{tabular}{|c|c|c|c|c|c|c|c|c|c|}
\hline Turma & \multicolumn{2}{|c|}{$2^{\circ}$ ano } & \multicolumn{2}{|c|}{$3^{\circ}$ ano } & \multicolumn{2}{|c|}{$4^{\circ}$ ano } & \multicolumn{2}{|c|}{$6^{\circ}$ ano } & \multirow[b]{2}{*}{ Total } \\
\hline Grupo & $\begin{array}{c}\text { Grupo } \\
\text { com } \\
\text { trocas }\end{array}$ & $\begin{array}{c}\text { Grupo } \\
\text { sem } \\
\text { trocas }\end{array}$ & $\begin{array}{c}\text { Grupo } \\
\text { com } \\
\text { trocas }\end{array}$ & $\begin{array}{c}\text { Grupo } \\
\text { sem } \\
\text { trocas }\end{array}$ & $\begin{array}{c}\text { Grupo } \\
\text { com } \\
\text { trocas }\end{array}$ & $\begin{array}{c}\text { Grupo } \\
\text { sem } \\
\text { trocas }\end{array}$ & $\begin{array}{c}\text { Grupo } \\
\text { com } \\
\text { trocas }\end{array}$ & $\begin{array}{c}\text { Grupo } \\
\text { sem } \\
\text { trocas }\end{array}$ & \\
\hline [p] & 10 & 12 & 6 & 11 & 11 & 11 & 2 & 9 & 72 \\
\hline [b] & 11 & 13 & 13 & 11 & 10 & 15 & 4 & 12 & 89 \\
\hline$[t]$ & 9 & 12 & 8 & 9 & 10 & 11 & 4 & 8 & 71 \\
\hline [d] & 6 & 11 & 7 & 9 & 5 & 8 & 2 & 6 & 54 \\
\hline$[\mathrm{k}]$ & 11 & 11 & 10 & 7 & 12 & 10 & 2 & 8 & 71 \\
\hline [g] & 9 & 12 & 9 & 9 & 7 & 15 & 6 & 7 & 74 \\
\hline \multirow{2}{*}{ Total } & 56 & 71 & 53 & 56 & 55 & 70 & 20 & 50 & \multirow{2}{*}{431} \\
\hline & \multicolumn{2}{|c|}{127} & \multicolumn{2}{|c|}{109} & \multicolumn{2}{|c|}{125} & \multicolumn{2}{|c|}{70} & \\
\hline
\end{tabular}

Fonte: Elaborado pela autora

Verifica-se a partir do Quadro 4 que há um número maior de tokens no grupo sem trocas, que totalizam 247, do que no grupo com trocas, com 184. Isso deve-se, possivelmente, a um maior número de dados descartados devido a uma má qualidade do áudio.

\section{Resultados e discussão}

Após coleta e apreciação dos dados, verificou-se que, conforme esperado, as trocas presentes na fala são menos expressivas do que aquelas que foram constatadas na escrita. Os dados de escrita contabilizam 7.300 produções, sendo 6.963 realizadas no ditado, com 5,6\% de trocas, e 337 na narrativa, com apenas $0,07 \%$ de trocas. Nos dados de fala, tem-se um total de 9.213 produções, sendo 8.605 no ditado, com $0,5 \%$ de trocas, e 609 na narrativa, onde trocas não foram identificadas.

No Quadro 5, é possível comparar as trocas presentes na fala e na escrita em cada uma das turmas, considerando-se o ditado, já que as trocas na narrativa são pouco expressivas. 
96 |Vergília Spiering Damé e Giovana Ferreira-Gonçalves

Quadro 5: Percentual de trocas na fala e na escrita no ditado

\begin{tabular}{|c|c|c|c|c|c|c|}
\hline & \multicolumn{3}{|c|}{ Fala } & \multicolumn{3}{c|}{ Escrita } \\
\hline Ano & Possibilidades & Trocas & $\%$ & Possibilidades & Trocas & $\%$ \\
\hline $2^{\circ}$ ano & 1.217 & 8 & 0,7 & 1.356 & 105 & 7,7 \\
\hline $3^{\circ}$ ano & 2.319 & 13 & 0,6 & 1.618 & 157 & 9,7 \\
\hline $4^{\circ}$ ano & 3.038 & 14 & 0,5 & 2.640 & 120 & 4,5 \\
\hline $6^{\circ}$ ano & 2.031 & 3 & 0,1 & 1.349 & 19 & 1,4 \\
\hline Total & 8.605 & 38 & 0,4 & 6.963 & 401 & 5,5 \\
\hline
\end{tabular}

Fonte: Elaborado pela autora

$\mathrm{Na}$ fala, o percentual de trocas, identificadas de outiva, não ultrapassa $1 \%$ em nenhuma das turmas; já na escrita, os percentuais são superiores a $1,4 \%$, atingindo aproximadamente $10 \%$ no $3{ }^{\circ}$ ano. Cabe salientar, também, que os índices de trocas na escrita diminuem gradativamente ao longo das séries, a partir do $3^{\circ}$ ano. Já na fala, os índices apresentam maior predomínio no $2^{\circ}$ ano, seguido do $3^{\circ}, 4^{\circ}$ e $6^{\circ}$.

Considerando as trocas por oclusivas, novamente na fala, ainda de outiva, e na escrita, conforme o Gráfico 1, o maior número de ocorrência é verificado nas oclusivas labiais, em especial a sonora, contrariando o que apontam Cristofolini (2008), Guimarães (2005), Zorzi (1997) e Miranda e Matzenauer (2010), quando a maioria das trocas foi verificada nas dorsais. $\mathrm{Na}$ fala, da mesma forma, chama atenção o alto índice de trocas com a labial sonora, já que essa seria uma das primeiras consoantes a ser adquirida. 
Gráfico 1: Percentual de trocas por oclusiva na fala e na escrita no ditado

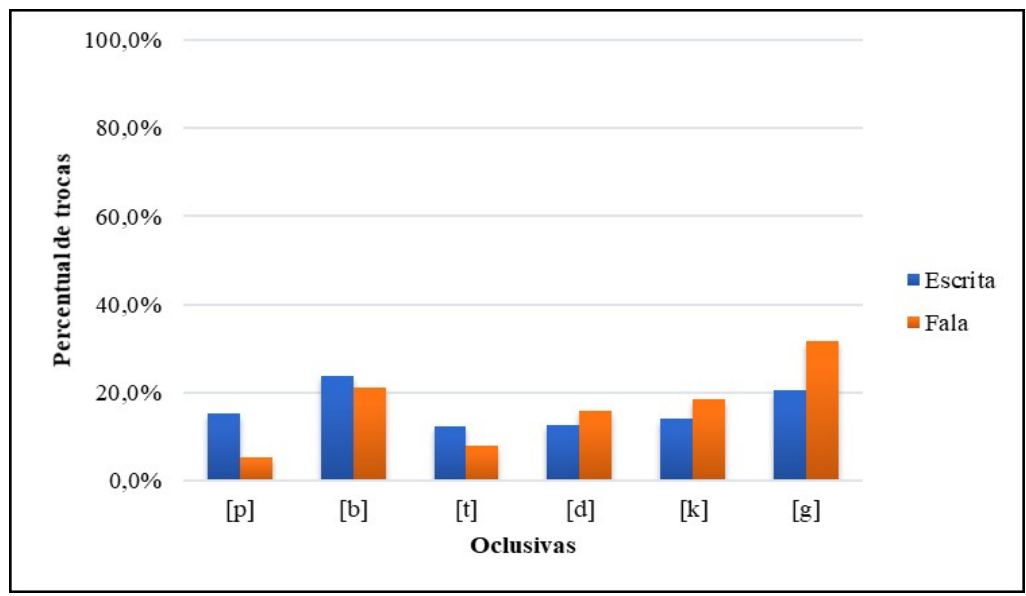

Fonte: Elaborado pela autora

Ao comparar as trocas na escrita e na fala, nota-se maior diferença entre ambas nos casos de [p] e [g], quando há, respectivamente, maior número de trocas na escrita, em relação à fala, e na fala em relação à escrita. Nos demais casos, com uma diferença menor, as trocas prevalecem na escrita para $[b]$ e $[t]$ e na fala, para $[d]$ e $[k]$. Cabe observar que o predomínio de trocas em algumas dessas consoantes é, por vezes, resultado da produção de um único participante, assim como relatou Zorzi (1997), a respeito do papel de poucos sujeitos nos índices obtidos.

Verifica-se, assim, que a exceção de [p] e [g], as trocas presentes na fala e na escrita parecem apresentar uma relação, no entanto, ao separar esses dados por série, essa relação se dissipa. O Gráfico 2 evidencia que as trocas na escrita são mais recorrentes do que na fala e que em cada ano há o predomínio de uma oclusiva como a mais frequente na ocorrência de trocas.

Ainda, confirma-se a maior probabilidade de trocas em oclusivas sonoras - tanto na fala quanto na escrita -, casos de dessonorização apontados por Zorzi (1997) e confirmados por Guimarães (2005) e Miranda e Matzenauer (2010), sendo, em sua maioria, para "g", nos $2^{\circ}$ e $6^{\circ}$ anos, para "d" no $3^{\circ}$ e para "b" no 4․ 
Gráfico 2: Percentual de trocas por série e oclusiva na fala e na escrita

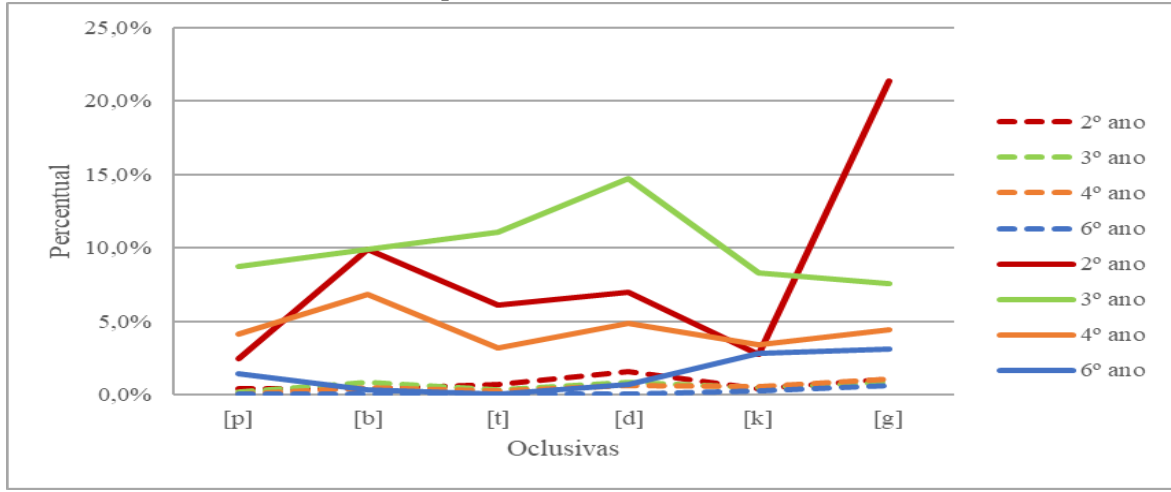

Fonte: Elaborado pela autora

Legenda: linha contínua $=$ dados de escrita; linha pontilhada $=$ dados de fala

Assim como ocorre para a escrita, na fala evidencia-se, ao longo das séries, uma redução no número de trocas, além de uma redução no número de segmentos em que essas trocas ocorrem. No $2^{\circ}$ e $3^{\circ}$ anos, há trocas com todas as oclusivas, no $4^{\circ}$ ano, não se verifica troca com [p], e, no $6^{\circ}$ ano, apenas para as dorsais foram constatadas trocas.

Diferenças, no entanto, são encontradas em relação à quantidade de trocas. Considerando a relação entre fala e escrita, sem a realização de uma análise acústica, verifica-se que o percentual de trocas na escrita é superior em todas as séries. Ainda, diante do fato de que as trocas na escrita estão concentradas em alguns sujeitos, ao observar a ocorrência de trocas na fala e escrita de cada um, constatou-se que aqueles sujeitos com maior número de trocas ortográficas são aqueles em que, pelo contrário, não foram verificadas trocas na fala, ao menos de outiva.

Ao colocar em destaque o papel do VOT, foi analisado um total de 431 produções, das quais os valores médios de duração de VOT e sua duração relativa estão dispostos na Tabela 2. Para as oclusivas sonoras, verificam-se médias dentro do esperado na literatura, entre $-70 \mathrm{~ms}$ e 100ms (KLEIN, 1999; CRISTOFOLINI, 2008). Para as oclusivas surdas, coronal e labial, observam-se valores pouco mais elevados do que o esperado, acima dos $28 \mathrm{~ms}$, sendo que, normalmente, a média reportada é de $25 \mathrm{~ms}$. As dorsais, que tendem a apresentar certa aspiração, os valores são superiores a $40 \mathrm{~ms}$, conforme esperado. 
A influência da fala na escrita das oclusivas: o papel do VOT em trocas ortográficas | 99

Tabela 2: Média geral de duração do VOT e duração relativa do VOT por oclusiva para as palavras controle

\begin{tabular}{|c|c|c|c|c|c|c|c|}
\hline & & [p] & [b] & {$[t]$} & [d] & {$[\mathrm{k}]$} & [g] \\
\hline \multirow{2}{*}{$\begin{array}{l}\text { VOT } \\
\text { (ms) }\end{array}$} & $\begin{array}{l}\text { Grupo s/ } \\
\text { trocas }\end{array}$ & 31,67 & 87,16 & 30,65 & 79,33 & 64,17 & 75,34 \\
\hline & $\begin{array}{l}\text { Grupo c/ } \\
\text { trocas }\end{array}$ & 28,18 & - & 32,09 & 73,73 & 48,15 & 67,41 \\
\hline \multirow{2}{*}{$\begin{array}{l}\text { DR } \\
\text { VOT } \\
(\%)\end{array}$} & $\begin{array}{l}\text { Grupo s/ } \\
\text { trocas }\end{array}$ & 8,18 & 20,37 & 6,88 & 18,07 & 15,31 & 16,95 \\
\hline & $\begin{array}{l}\text { Grupo c/ } \\
\text { trocas }\end{array}$ & 8,03 & 19,02 & 8,27 & 18,70 & 13,40 & 19,11 \\
\hline
\end{tabular}

Fonte: Elaborado pela autora

Esses valores médios se comportam de maneira próxima daqueles apresentados por Cristofolini (2008), em que o grupo controle apresenta valores de duração mais elevados do que o grupo sem trocas, o que só não é constatado para [t]. O argumento proposto por Sanches (2003), de que as oclusivas sonoras apresentam uma duração de VOT menor, quase próxima a (0), não foi constatado.

Observando os valores de duração relativa do VOT, que permitem verificar se a taxa de elocução não influência no valor de duração de VOT, nota-se similaridade entre os valores de [k] e [g], mais próximos no grupo sem trocas, mas também presente no grupo com trocas, o que poderia indicar uma duração de VOT ainda não estabilizada nesses segmentos, que não é verificada nos demais pares mínimos, quando o percentual ocupado pela oclusiva sonora é sempre mais elevado. Tal fato pode indiciar uma etapa de ajuste articulatório, revelando que ou as oclusivas surdas estão apresentando um VOT (+) mais elevado do que o esperado ou as sonoras estão apresentando um VOT (-) menor do que o esperado. Entretanto, a diferença entre os grupos sem trocas e o com trocas, considerando as médias do VOT e de sua duração relativa por oclusiva de cada sujeito, não é significativa e essa hipótese precisa de um número maior de dados para ser confirmada.

Diferenças significativas foram constatadas - por meio do teste Mann-Whitney -, apenas na duração relativa do VOT de [k] em contexto 
de $/ \mathrm{u} /(\mathrm{U}=0,000, \mathrm{p}=0,006)$, na duração relativa do VOT de [d] em sílaba $\mathrm{CV}(\mathrm{U}=-22,000, \mathrm{p}=0,037)$, na duração relativa do VOT de $[\mathrm{k}]$, quando em sílaba CV e seguido da vogal $/ \mathrm{u} /(\mathrm{U}=-0,000, \mathrm{p}=0,046)$. Os casos com $[\mathrm{k}]$ apresentam maiores valores de VOT no grupo sem trocas, enquanto o com [d], maiores valores no grupo com trocas.

Observa-se, assim, a partir da análise estatística aplicada nos valores de duração de VOT que o contexto parece ser necessário para responder a possível influência da fala na escrita. A fim de melhor relacionar as duas modalidades, testes estatísticos foram aplicados também nos dados de escrita e de fala analisados de outiva. Nesses casos o contexto também parece exercer seu papel. No que concerne a influência do contexto na escrita, Damé (2017) reporta, a respeito desse mesmo corpus, que há indícios de influência do contexto na ocorrência de trocas ortográficas.

Considerando contexto vocálico, tonicidade, posição da oclusiva na palavra e estrutura silábica, Damé (2017) aponta os seguintes resultados: (i) contexto vocálico: primeiramente por meio do teste Friedman $\left(\left(\mathrm{x}^{2}(2)=16,687, \mathrm{p}=0,000\right)\right.$ verifica-se diferença significativa para grafia de "b". A partir do pareamento das três vogais utilizadas "a', "i" e "u", foi verificado, por meio do teste Wilcoxon $(Z=-2,972, p=$ 0,003), para /a/ $\mathrm{x} / \mathrm{i} /$, e $(\mathrm{Z}=-3,517, \mathrm{p}=0,000)$ para $/ \mathrm{a} / \mathrm{x} / \mathrm{u} /$, que a vogal /a/ favorece a grafia dessa consoante; (ii) tonicidade: mostra-se significativa a influência do contexto tônico, para ocorrência a escrita de "t", evidenciada por meio do teste Wilcoxon $(Z=-2,383, p=0,017)$; (iii) posição da oclusiva na palavra: a posição medial na palavra também se mostrou relevante para a ocorrência adequada de ' $\mathrm{t}$ ', a partir do teste Wilcoxon $(Z=-2,104, p=0,035)$ e; (iv) estrutura silábica: a estrutura CV se mostrou mais provável à ocorrência de acertos para " $\mathrm{p}$ " $(\mathrm{Z}=-2,483, \mathrm{p}=$ 0,013), "t" $(Z=-2,561, p=0,010)$ e "d" $(Z=-2,876, p=0,004)$, significância constatada por meio do teste Wilcoxon.

$\mathrm{Na}$ fala, considerando-se os mesmos contextos da escrita, verificamse os seguintes resultados: (i) contexto vocálico: significância na produção de $[b]$, verificada a partir do teste Friedman $\left(\left(x^{2}(2)=7,000, p=0,030\right)\right.$. Pareadas as vogais, por meio do teste Wilcoxon, a diferença se mostrou significativa entre $[\mathrm{a}] \mathrm{x}[\mathrm{u}]-\mathrm{Z}=-2,032, \mathrm{p}=0,042-\mathrm{e}$ entre $[\mathrm{i}] \mathrm{x}[\mathrm{u}]-\mathrm{Z}=$, $1,997, p=0,046$ - sendo a vogal $[u]$ mais propicia a ocorrência de trocas para essa oclusiva; (ii) tonicidade: foi identificada diferença na produção de $[k]$, evidenciada a partir do teste Wilcoxon $(Z=-2,388, p=0,017)$, sendo verificado maior número de trocas em contextos átono; (iii) posição 
da oclusiva na palavra: não apresentou diferenças significativas e; (iv) estrutura silábica: verifica-se que [d] mantém um maior número de trocas em sílaba CCV, o que foi verificado pelo teste Wilcoxon $(Z=-2,023, p=$ 0,043). A estrutura silábica é significativa também para [g], sendo superiores as trocas em sílaba CCV, resultado obtido por meio do teste Wilcoxon $(Z=-2,433, p=0,015)$.

Comparando os resultados obtidos na escrita, fala e análise acústica observa-se pouca convergência. Não é verificada diferença significativa para $[\mathrm{d}]$ e $[\mathrm{k}]$ na fala e escrita no que se refere à vogal $[\mathrm{u}]$ e nem mesmo no que se refere à estrutura $\mathrm{CV}$. Ao contrário, para [d] maior número de trocas na fala é verificado em sílaba CCV, sendo a sílaba $\mathrm{CV}$ mais propícia a ocorrência de acertos na escrita de "d". No caso de [k], os valores mais altos na duração relativa de VOT no grupo com trocas ortográficas confirma os resultados de Cristofolini (2008), no qual o grupo controle, sem trocas, apresenta os valores mais altos de duração de VOT.

Diante de tais resultados, o papel do VOT sobre a ocorrência de trocas ortográficas não parece ser decisivo, ainda que esteja presente, como pode ser constatado nos casos em que diferença significativa foi verificada. No mais, é possível que outros fatores acústicos, e mesmo articulatórios, possam juntos responder de forma mais eficaz pela ocorrência de trocas ortográficas que não necessariamente são detectadas na fala de outiva.

\section{Considerações finais}

As trocas ortográficas nos segmentos oclusivos aparecem em número reduzido, mas, ainda assim, representam material suficiente para que sua ocorrência seja verificada. Comparando fala e escrita, percebe-se que as trocas na fala aparecem em número pouco expressivo, o que indica, como esperado, que já não estão presentes na fala, ao menos no que é possivel identificar de outiva.

Por meio de análise acústica, considerando a duração do VOT, verificou-se que o VOT das oclusivas dorsais parece ser aquele com maior indício de refinamento articulatório, já que os valores de duração relativa desse par mínimo são bastante similares, o que não ocorre nos pares de labiais e coronais. Testes estatísticos confirmam a diferença de valores 
entre o grupo sem trocas quando comparados ao grupo com trocas, que apresentam valores menores de duração relativa para [k].

No que se refere aos demais segmentos, os resultados, apenas considerando o VOT como parâmetro acústico, não parecem ser satisfatórios para indicar a influência da fala na ocorrência de trocas ortográficas. Para tanto, talvez seja necessário ampliar o leque de parâmetros acústicos controlados ou mesmo verificar o papel da articulação, por meio de ferramentas que permitam observar a movimentação da língua.

\section{REFERÊNCIAS}

ABAURRE, M. B. M. A relação entre escrita espontânea e representações linguísticas subjacentes. Verba Volant, Vol. 2, pp.167-200, Pelotas: Editora UFPEL, 2011.

BONATTO, M. T. R. L. Vozes Infantis: a caracterização do contraste do vozeamento dos segmentos plosivos do português brasileiro na fala de crianças de 3 a 12 anos. Tese de Doutorado. Pontifícia Universidade Católica de São Paulo. São Paulo, 2007.

BONILHA, G. F. G. Aquisição fonológica do português brasileiro: uma abordagem conexionista da Teoria da Otimidade. Tese (Doutorado em Letras) - Pontifícia Universidade Católica do Rio Grande do Sul, Porto Alegre, 2004.

CRISTOFOLINI, C. Trocas ortográficas: um estudo a partir de análises acústicas. Dissertação de Mestrado. Programa de Pós-Graduação em Linguística. Universidade de Santa Catarina, 2008.

CRISTOFOLINI, C. Gradiência na fala infantil: caracterizando acústica de segmentos plosivos e fricativos e evidências de um período de "refinamento articulatório". Tese de Doutorado. Universidade Federal de Santa Catarina, Florianópolis, 2013.

DAMÉ, Vergília Spiering. Aquisição da escrita das consoantes plosivas: aspectos acústicos e articulatórios. Dissertação (Mestrado em Letras). Programa de Pós-Graduação em Letras, Universidade Federal de Pelotas, 2016.

DAMÉ, V. S; FERREIRA-GONÇALVES, G. Trocas ortográficas de consoantes oclusivas no português brasileiro. Signótica, v.29, p.504 $527,2017$. 
. As plosivas nas séries iniciais: o papel do contexto na ocorrência de trocas ortográficas. Signo, v.43, p.32 - 42, 2018.

FREITAS, G. C. M. Sobre a aquisição das plosivas e nasais. In: LAMPRECHT, R (org). Aquisição Fonológica do Português. Porto Alegre: Artmed, 2004.

GUIMARÃES. M, R. Um estudo sobre a aquisição da ortografia nas séries iniciais. Dissertação (Mestrado em Educação) - Faculdade de Educação, UFPel, Pelotas, 2005.

KLEIN, S. Estudo do VOT no Português Brasileiro. Dissertação (Mestrado em Linguística) - Universidade Federal de Santa Catarina, Florianópolis, 1999.

LAMPRECHT, R., R. Perfil de aquisição normal da fonologia do Português. Descrição longitudinal de 12 crianças: 2:9 a 5:5. Tese (Doutorado em Letras) - Instituto de Letras e Arte, PUCRS, 1990.

LISKER, L; ABRAMSON, A. A cross-language study of voicing in initial stops: acoustical mearuraments. Words, 20, 384-422, 1964.

MIRANDA, A. R. M. Um estudo sobre o erro ortográfico. In: HEINING, O.; FRONZA, C. de A. (Org.). Diálogos entre linguística e educação. 1 ed. Blumenau: EDIFURB, 2010.

. A Fonologia em dados de Escrita inicial de crianças brasileiras. Revista Linguística, vol. 30, n. 2, p. 45-80, 2014.

MIRANDA, A. R. M.; MATZNAUER, C. L. B. Aquisição da fala e da escrita: relações com a Fonologia. Cadernos de Educação. Pelotas, n. 35. p. 359-404, 2010.

RODRIGUES, L. L. A complexidade das relações ortográfico-fônicas na aquisição da escrita: um estudo com crianças da aquisição infantil. Tese Instituto de Estudos da Linguagem, UNICAMP, Campinas, 2012.

SANCHES, A. P. Análise espectrográfica da fala de crianças com trocas grafêmicas nos plosivos surdos e sonoros. Dissertação (Mestrado): Universidade Federal de Maringá, 2003.

ZORZI, J. L._A apropriação do sistema ortográfico nas quatro primeiras séries do 1 ograu. Unicamp. Faculdade de Educação. Campinas, 1997.

Recebido em: 27/03/2019

Aceito em: 12/04/2019 